\title{
Metamemories of memory researchers
}

\author{
DENISE C. PARK \\ University of Georgia, Athens, Georgia \\ ANDERSON D. SMITH \\ Georgia Institute of Technology, Atlanta, Georgia \\ and \\ JOHN C. CAVANAUGH \\ Bowling Green State University, Bowling Green, Ohio
}

\begin{abstract}
In the present study, a metamemory questionnaire was completed by three groups of individuals: memory research psychologists who attended a small international convention on everyday memory processes in the aged, academic psychologists with a limited knowledge of the memory literature, and nonpsychologist college professors. There was little evidence that memory psy. chologists reported using strategies to remember things that were different from the strategies of other academics. The most used and most recommended technique for remembering was to write things down, followed by general internal mnemonic systems such as organization and rehearsal. The least used and least recommended strategies for all three groups were formal mnemonic systems, such as the peg-word system or the method of loci.
\end{abstract}

In recent years, psychologists have become increasingly concerned with understanding everyday memory processes and strategies. One approach that has been used to study these processes has been to survey people's perceptions about the circumstances under which their memories are good or poor, as well as to ask people what particular techniques they rely upon to remember things (Herrmann, 1982). This approach falls under the rubric of metamemory, which is the knowledge that individuals have about their memory (Cavanaugh, Grady, \& Perlmutter, 1983). To date, this research has focused on children, mentally retarded persons, college students, adults, and the elderly. However, researchers have not investigated the knowledge of memory researchers themselves. One might expect that memory researchers would be metamemory experts, knowing about the most efficient ways of learning and remembering information, and base their recommendations to others concerning these issues on their wealth of professional knowledge. In the research reported here, we examined this notion by comparing the self-reported use of memory strategies, and the types of strategies that would be recommended to others, on the part of three groups of individuals: memory researchers, other psychologists who were not experts in memory, and nonpsychologist university faculty members.

The authors thank Helen Palmer, Bill Dudley, and Roger Morrell for assistance in scoring and data analysis. The data for the memory psychologists were collected at a conference on aging and memory (Poon, Rubin, \& Wilson, 1989). Requests for reprints should also be sent to Denise C. Park, Gerontology Center, 100 Candler Hall, University of Georgia, Athens, GA 30602 .
The present investigation draws upon and enhances previous work on the self-reported use of memory strategies in everyday life (e.g., Cavanaugh et al., 1983; Harris, 1980; Intons-Peterson \& Fournier, 1986). In particular, these earlier studies have documented that ordinary people tend to use external memory strategies (those involving the use of tangible physical aids, such as lists or calendars) much more frequently than internal aids (those that are internal to oneself, such as imagery or rehearsal).

There are two detailed studies on the reported use of strategies (Harris, 1980; Intons-Peterson \& Fournier, 1986). In the Harris study, strategies were divided into three major categories: internal aids, external aids, and general internal strategies. Internal aids were formal mnemonic strategies that required training to use, such as the method of loci, the peg-word system, or the linking of items through a story. External aids were such things as notepads, asking others to remind one, and placing objects where they might be remembered. Subjects received detailed questionnaires about the frequency with which these strategies were used. Harris notes that general internal strategies such as organization and elaboration were not studied, because these strategies are representative of "normal memory operation,"-although he does note the difficulty in discriminating general internal strategies from internal mnemonic aids. In general, Harris found that subjects reported a very low usage of internal mnemonic aids that required any formal preparation, and a high usage of external aids.

Intons-Peterson and Fournier (1986) not only investigated what strategies people used to remember, but differentiated particular circumstances for which one 
strategy was preferred over another. Subjects reported a slightly higher usage of external aids than of general internal strategies, with little use of formal mnemonic systems. There were some situational preferences for using external aids for future remembering rather than past remembering, but there nevertheless was an overall preference for external aids for both types of memory.

One problem with the research conducted on these issues to date is that the self-reported preference of external aids over internal aids may be artifactual. That is, the people who are typically participants in the research may simply not be aware of the effectiveness of internal aids such as the method of loci or imagery. It is arguable that individuals with such knowledge-psychologists who are active memory researchers-would report a much higher rate of usage of such formal systems. If this is the case, the findings of higher use of external aids may occur due to lack of knowledge rather than active avoidance of such internal strategies. Alternatively, if external aids are still reported to be used much more often by persons who are experts in the field, then the differences may reflect an informed decision not to use internal strategies. Finally, because most theoretical research in the field of memory has been concentrated on general internal strategies, it is possible that memory psychologists' use and recommendations will be more heavily biased towards these strategies.

To address these issues, three groups of individuals completed questionnaires concerning their use of memory strategies in everyday life: psychologists who were active memory researchers, psychologists who were not memory experts, and nonpsychologist academicians. The respondents were asked to indicate what memory strategies they used, which strategies they would or would not recommend to others, and why they would make these recommendations.

\section{METHOD}

\section{Subjects}

A total of 69 memory researchers, 61 nonmemory psychologists, and 60 nonpsychologist college professors completed the questionnaire. The memory researchers were participants at a small international memory conference on everyday memory and aging, held at Cape Cod, Massachusetts. The proceedings of the conference have been published (Poon, Rubin, \& Wilson, 1989). All those present were interested in memory research, some specializing in aging and others not. All of those who attended were asked to complete the questionnaire at a group meeting, and the experimenters were not aware of any refusals. Of the 69 people completing the survey, 10 were discarded from further analysis because they did not appear to be experts in memory. That is, to be included, participants had to indicate that they had either (1) published at least one paper on human memory, or (2) considered their primary research interest to be human memory. Of the 59 included, 43 subjects $(73 \%)$ responded affirmatively to both questions. The second group of subjects were 61 psychologists drawn from four different university psychology departments in the United States. Of these, 18 were excluded because screening questions indicated that they described themselves as having a moderate or greater amount of knowledge about the psychology of memory, mnemonic systems, or memory and aging. Finally, the third group consisted of nonpsychologists in other departments at the same four universities. The same reasons for exclusion were used for these individuals. Of the 60 nonpsychologists who completed the questionnaire, six were excluded from subsequent analyses. The mean ages for the memory psychologists, other psychologists, and nonpsychologists included in the analyses were $41.15,43.49$, and 47.18. Analyses of covariance with age as a covariate did not change any of the analyses to be reported. A total of 111 males and 45 females were included in the analyses.

\section{Stimulus Materials}

A memory questionnaire divided into three major sections was completed by all subjects. In the first section, general information about research interests, gender, and age was collected. In the second section, the subjects rated the frequency with which they used 18 different mnemonic techniques on a scale from 1 to 5 , with "never use" and "use daily" as endpoints. An extra sheet that defined each item was provided with each questionnaire, and, in some cases, it provided a specific example. Formal mnemonic systems, which require some training to be used effectively, were represented by six items: the peg-word system, the method of loci, the name-face technique, the initial letter sequence, linking items through a story, and converting digits to letters to form words. More general memory strategies were represented by two subdivisions: image-based and general, non-image-based strategies. The image-based strategies rated included the use of bizarre images, the use of interacting images, and visualizing concrete words. More general strategies were represented by rehearsal, organization, semantic elaboration, rhyming, and verbal association. Finally, external memory aids were represented by lists and notes, physical reminders such as a string around the finger, telling others to remind one, and placing items where they wouldn't be forgotten.

In the last section of the questionnaire, the subjects were asked to rank the three techniques from any of the strategies or techniques in the questionnaire that they would be most likely to recommend and least likely to recommend to others to help them remember. A checklist followed, asking what variables affected their recommendations for helpful techniques. The choices included (1) "ease of use," (2) "compatibility with view of how memory functions," (3) "literature demonstrates technique works," (4) "clinical experience," (5) "personal experience," (6) "intuition," and (7) "don't know." The subjects were to check all reasons that applied.

\section{Procedure}

The memory psychologists received their questionnaires at the end of a meal, preceding a discussion to be held in the same room. All questionnaires were completed anonymously and returned prior to the beginning of the discussion. The nonmemory psychologists and nonpsychologists were acquaintances and colleagues of the authors (as were the memory psychologists). They were contacted by mail and received a brief cover letter, a consent form, a questionnaire, and two return envelopes. The subjects were instructed to return the consent form under separate cover, to protect their anonymity.

\section{RESULTS}

The primary data of interest were the ratings of frequency of usage of the different memory techniques and strategies. A complete summary of these ratings as a function of group appears in Table 1 . A multivariate analysis of variance (MANOVA) was conducted, with group as the independent variable and the 18 ratings on the vari- 
Table 1

Frequency of Use and Ordinal Rankings within Each Group for Memory Techniques as Used by Memory Psychologists, Other Psychologists, and Nonpsychologists

\begin{tabular}{|c|c|c|c|c|c|c|}
\hline \multirow{2}{*}{$\begin{array}{l}\text { Memory } \\
\text { Technique }\end{array}$} & \multicolumn{2}{|c|}{ Memory Psychologists } & \multicolumn{2}{|c|}{ Other Psychologists } & \multicolumn{2}{|c|}{ Nonpsychologists } \\
\hline & Freq. & Rank & Freq. & Rank & Freq. & Rank \\
\hline Peg-word & 1.20 & 18 & 1.25 & 17 & 1.25 & 17 \\
\hline Loci & 1.39 & 15 & 1.44 & 16 & 1.63 & 14 \\
\hline Narne-Face & 1.81 & 11 & 1.65 & 14 & 1.72 & 12 \\
\hline Initial letters & 1.81 & 11 & 1.95 & 9 & 1.82 & 11 \\
\hline Linking by story & 1.49 & 14 & 1.51 & 15 & 1.57 & 16 \\
\hline Digit-letters & 1.24 & 17 & 1.09 & 18 & 1.13 & 18 \\
\hline $\begin{array}{l}\text { Bizarre images } \\
\text { Interactive }\end{array}$ & 1.78 & 13 & 1.84 & 10 & 1.59 & 15 \\
\hline images & 1.83 & 10 & 1.70 & 13 & 2.18 & $9+$ \\
\hline Visualizing words & 2.06 & 9 & 2.49 & 8 & 2.33 & 7 \\
\hline Rehearsal & 3.49 & 4 & 3.47 & 2 & 3.17 & 3 \\
\hline Organization & 3.63 & 2 & 3.19 & 3 & 3.07 & $4 \ddagger$ \\
\hline Elaboration & 2.69 & 6 & 2.77 & 5 & 2.57 & 6 \\
\hline Association & 2.37 & 7 & 2.56 & 7 & 2.26 & 8 \\
\hline Rhyming & 1.29 & 16 & 1.79 & 11 & 1.72 & $12 *$ \\
\hline Lists and notes & 4.49 & 1 & 4.51 & 1 & 4.30 & 1 \\
\hline Physical reminder & 2.29 & 8 & 1.72 & 12 & 1.91 & $10 \dagger$ \\
\hline Telling others & 3.02 & 5 & 2.67 & 6 & 2.83 & 5 \\
\hline Place method & 3.53 & 3 & 3.16 & 4 & 3.42 & 2 \\
\hline
\end{tabular}

Note-Frequency of use is rated on a 5-point scale $(1=$ lowest, $5=$ highest $)$. "Significant difference $(p<.002)$. †Marginally significant difference $(p<.06)$. †Marginally significant difference $(p<.08)$.

ous memory techniques as dependent variables. The MANOVA revealed that the three groups of subjects were different [Wilks' criterion $F(36,272)=2.123, p<.001$, Wilks' Lambda $=.609$ ]. Individual analyses of variance were then conducted on each of the 18 dependent measures. In general, the analyses revealed that the groups differed from one another on only a few dependent measures. The individual ANOVAS yielded a significant main effect for rhymes $[F(2,153)=6.67, p<.002]$, and marginally significant effects for interacting images $[F(2,153)$ $=2.88, p<.06]$, organization $[F(2,153)=2.57$, $p<.08]$, and the use of physical reminders $[F(2,153)$ $=2.83, p<.06]$. An examination of Table 1 reveals that the rhyme effect was significant, because memory psychologists used rhymes as a mnemonic strategy less than the other two groups. Memory psychologists relied on organization and physical reminders more than the other two groups. The effect of interacting images approached significance, because nonpsychologists were somewhat more likely to use it than were the other two groups. An examination of Table 1 also reveals that use of formal mnemonic systems and image-based strategies was quite low, whereas use of external memory aids and general memory strategies were used frequently. Because age has been demonstrated in the past to sometimes affect subjects' metamemory judgments, univariate analyses were also conducted with age as a covariate. These covariate analyses did not alter the results reported above.

Because we had hypothesized that memory psychologists would be most likely to differ from the others in their use of general, non-image-based strategies, we partitioned the 18 dependent measures collected for each subject into the four groups described earlier, summed them, and calculated a mean for each group of items for each subject. The first group consisted of formal mnemonic systems and included peg-word, loci, name-face, initial letters, stories, and digit-letters. The second group comprised image-based strategies, which included three measures: bizarre images, interacting images, and concrete words. The third group comprised general memory strategies and included rehearsal, organization, elaboration, and association. Because theoretical considerations have demonstrated that rhymes are not useful as mnemonic techniques (Craik \& Tulving, 1975), rhymes were not included in this category or any other. The fourth group consisted of lists, physical reminders, telling others, and the place method. A MANOVA conducted on these four aggregated dependent variables, with subject grouping (memory psychologist, other psychologist, or nonpsychologist) as the independent variable, did not reach significance [Wilks's criterion $F(8,300)=1.40, p>.19$ ]. Thus, there was no support for the hypothesis that memory psychologists differed from the other groups in their use of classes of mnemonic strategies.

An examination of the ranked ratings within each group displayed in Table 1 provides further insight into the homogeneity of the ratings across groups. All three groups rated peg-word, loci, digit-letters, and stories in their bottom five ratings. Similarly, all groups assigned their top five ratings to rehearsal, organization, use of lists, telling others to remind them, and physical placement. Thus, the analysis suggests in general that there is tremendous agreement in subjects' ratings of which methods for remembering they use or do not use, regardless of train- 
ing. It is notable that memory psychologists deviated from the other two groups primarily in their ratings of rhymes, as they placed rhyming as their third least frequently used strategy, whereas this strategy was ranked much higher by the other two groups.

In the final section of the questionnaire, subjects were asked which of the 18 strategies they would be most likely and least likely to recommend, as well as what their basis was for making these recommendations. The five items at each extreme for each group appear in Table 2, and the results are characterized largely by their homogeneity, since there was little evidence for substantial difference among the three groups (Kendall's $W=.92$; average $r_{\mathrm{s}}$ $=.88$ ). For the most recommended items, four of the top five items were the same across all three groups, and these included lists and notes, organization, rehearsal, and the place method. Memory psychologists were more likely to recommend telling others to remind one as one of the top five, whereas the other two groups included elaboration in the top five. Unlike the memory psychologists, the other psychologists included telling others on the least recommended list.
Table 3 displays the reasons for recommending these preferred techniques. The top two reasons for all three groups were "personal experience suggested they worked" and "ease of use." Beyond this, the groups did not differ substantially in their ordinal rankings of the seven listed reasons (Kendall's $W=.86, r_{s}=.79$ ). Not surprisingly, however, memory psychologists were considerably more likely to indicate that their conceptual view of memory, the memory literature, and their clinical experiences affected their judgments than were the other two groups. Despite these differences in the basis for recommendations, the recommendations themselves differed little across groups.

There was also general agreement about strategies that would not be recommended, as is shown in Table 2 . All three groups rated the digit-letter technique as their least recommended strategy, followed by the peg-word systems. All three groups also included method of loci in their bottom five. The groups differed on the remaining two strategies, with rhymes and bizarre images for memory psychologists, whereas other psychologists included telling others and linking by story in their bottom

Table 2

Top Five Items Most and Least Recommended as Memory Aids

\begin{tabular}{|c|c|c|c|c|c|c|}
\hline \multirow{2}{*}{$\begin{array}{l}\text { Memory } \\
\text { Technique }\end{array}$} & \multicolumn{2}{|c|}{ Memory Psychologists } & \multicolumn{2}{|c|}{ Other Psychologists } & \multicolumn{2}{|c|}{ Nonpsychologists } \\
\hline & Proportion & Rank & Proportion & Rank & Proportion & Rank \\
\hline \multicolumn{7}{|c|}{ Most Recommended } \\
\hline Lists and notes & .712 & 1 & .791 & 1 & .278 & 4 \\
\hline Organization & .627 & 2 & .372 & 3 & .315 & 2 \\
\hline Rehearsal & .254 & 3 & .489 & 2 & .296 & 3 \\
\hline Place method & .186 & 4 & .256 & 4 & .333 & 1 \\
\hline Telling others & .169 & 5 & & & & \\
\hline Elaboration & & & .233 & 5 & .204 & 5 \\
\hline \multicolumn{7}{|c|}{ Least Recommended } \\
\hline Digit-letter & .508 & 1 & .581 & 1 & .537 & 1 \\
\hline Peg-word & .322 & 2 & .326 & 2 & .315 & 2 \\
\hline Rhyming & .305 & 3 & & & & \\
\hline Loci & .203 & 4 & .232 & 4 & .241 & 4 \\
\hline Bizarre images & .203 & 4 & & & .241 & 4 \\
\hline Telling others & & & .256 & 3 & & \\
\hline Linking by story & & & .209 & 5 & .259 & 3 \\
\hline
\end{tabular}

Note-Columns show proportions of subjects in each category who included the particular item as one of the three most or three least recommended items, and ordinal rankings within each group, with low rankings referring to the most frequent responses.

Table 3

Reasons for Recommending Memory Techniques as Desirable

\begin{tabular}{|c|c|c|c|c|c|c|}
\hline \multirow[b]{2}{*}{ Memory Technique } & \multicolumn{2}{|c|}{ Memory Psychologists } & \multicolumn{2}{|c|}{ Other Psychologists } & \multicolumn{2}{|c|}{ Nonpsychologists } \\
\hline & Proportion & Rank & Proportion & Rank & Proportion & Rank \\
\hline Personal experience & .830 & 1 & 1.00 & 1 & .926 & 1 \\
\hline Ease of use & .729 & 2 & .721 & 2 & .630 & 2 \\
\hline $\begin{array}{l}\text { Compatible with view of } \\
\text { how memory functions }\end{array}$ & .542 & 3 & .233 & 3 & .259 & 4 \\
\hline $\begin{array}{l}\text { Scientific research } \\
\text { supports use }\end{array}$ & .322 & 4 & .186 & 4 & .037 & 7 \\
\hline Intuition & .254 & 5 & .139 & 5 & .315 & 3 \\
\hline Clinical experience & .237 & 6 & .069 & 7 & .074 & 6 \\
\hline Don't know & .034 & 7 & .093 & 6 & .111 & 5 \\
\hline
\end{tabular}

Note-Columns show proportions of subjects in each group who listed that particular reason for recommendation, along with ordinal rankings within each group. 
five. Finally, nonpsychologists included bizarre images and linking by story. Generally, all three groups were least likely to recommend formal mnemonic systems that require preparation and training for use.

\section{DISCUSSION}

The major conclusions that can be drawn from this study are the following: First, there are only a few instances in which memory researchers report using memory strategies that differ from those used by other academiciansboth psychologists and nonpsychologists. Second, there is no evidence that even knowledgeable individuals, such as memory researchers, use formal mnemonic systems themselves, or recommend that others do so. Third, the most popular strategies, both in terms of personal use as well as recommendations for others, are either those that depend on external aids, such as notes and lists, or those that are general and internal, such as organization and rehearsal. Fourth, although recommendations of experts and nonexperts do not differ substantially, memory experts are somewhat more likely to cite their professional knowledge as the basis for their recommendations. Finally, in the few areas in which memory experts and nonexperts showed differences, the differences did appear to be related to theoretical considerations regarding memory structure and processes. Each of these conclusions is discussed below, with particular emphasis on the implications of these findings for contemporary memory research and theory.

The finding that memory researchers use essentially the same strategies as nonexperts to remember might initially appear to be paradoxical, and a superficial interpretation of this finding might be that memory researchers know so little about memory function that their own cognitive processes are unaffected by their research. We believe, however, that the more appropriate interpretation is this: Memory researchers study normal memory and cognitive functioning, and thus tend to focus on techniques commonly used by many individuals, including themselves. The memory researchers' strategies for remembering did not differ from those of nonexperts because the techniques reportedly used were fundamental to normal cognitive functioning, regardless of training or profession. This view is consonant with the emphasis that memory researchers have placed on understanding the structure and processes associated with human memory for the past century, with less importance assigned to individual differences and to the formal study of mnemonic devices and memory facilitation techniques. The fact that highly knowledgeable individuals tend to use sophisticated mnemonic techniques no more than less sophisticated individuals suggests that this emphasis on structure and function may have been well placed.

It might also be noted that the metamemory literature also provides data which suggest that individual difference variables are unlikely predictors of performance on metamemory questionnaires that focus on strategies.
Perlmutter (1978) found that neither age nor socioeconomic status influenced reported strategy use, and Dixon and Hultsch (1983) reported a similar finding for adult age. At the same time, it is important to note that these findings do not preclude the possibility that individual difference variables predict differences in actual strategy use. For example, organizational difficulties increase with age (A. D. Smith, 1980). Furthermore, Dixon and Hultsch (1983) found that knowledge about strategies predicted memory performance in young adults, but not in old subjects. Thus, although the present study suggests that memory researchers do not differ from other PhDs in the strategies with which they claim to remember things, their actual use of strategies may differ from those of other groups studied. Both Herrmann (1983) and Morris (1983) suggest that validity of metamemory questionnaires is suspect, even though the reliability is high. Thus, although these questionnaire reports suggest that strategy usage does not vary among groups of psychologists, only direct measures of organization, clustering, and other strategic measures of recall would address this issue.

The second finding, that even individuals knowledgeable about formal mnemonic systems do not use them reliably, may surprise some individuals. There are psychologists who believe that the use of formal mnemonic systems can be an important aspect of everyday memory function, and who advocate training in these methods as a mechanism for improving everyday memory functioning (West, 1985). However, the present findings both support and extend the work of both Harris (1980) and IntonsPeterson and Fournier (1986), who found little evidence that adults used formal mnemonic systems. It is clear that even individuals who understand the intricacies of formal mnemonics have a low rate of usage. It is improbable that the memory psychologist sample was unfamiliar with systems that are described in most undergraduate texts of cognition.

Memory psychologists may have reported using mnemonic devices so rarely because they recognize that although the devices are effective in limited situations, they require a substantial investment of cognitive effort as well as training time to be used advantageously. Memory psychologists, like other individuals, may be willing to rely on external aids and general internal strategies rather than to devote the effort required to effectively use formal mnemonic systems.

An alternative interpretation is that although the memory psychologists knew about the effectiveness of formal mnemonic systems, these systems were applicable to only a few situations in their everyday lives. Bartlett, in his book Remembering, stated that "literal recall is extraordinarily unimportant" (1932, p. 204). Perhaps Bartlett's astute observation provides the reason formal mnemonics are rarely used-there are not a large number of situations in everyday life in which literal memory is required. Again, this finding suggests the appropriateness of the focus of contemporary memory research on structure and process, because there is little evidence that 
formal, practical techniques for memory facilitation have much appeal to even knowledgeable individuals.

The third finding, that external devices and general memory strategies were most highly recommended by all groups, is interesting. For both groups of psychologists, by far the most popular recommendation was to write things down. Seventy-five percent of the two groups recommended this as a favored technique, a finding consonant with those reported by Harris (1980) and IntonsPeterson and Fournier (1986). Nonpsychologists were less likely to recommend writing things down (mean of $28 \%$ ), but they gave their highest recommendation to another external aid, the place method (33\%). All three groups reported using lists and notes as their primary means of remembering. This finding is perhaps where there is some divergence between memory psychologists' personal practices and contemporary research. There is little emphasis in traditional memory research on understanding the interplay between external aids and internal strategies for remembering. Perhaps this is because it is obvious that the human memory is a fallible system and that one must use external means (primarily written and computerized information) to guarantee retention. Nevertheless, the finding that writing things down is a primary mechanism for remembering in everyday life suggests that research on everyday memory might focus more on the role of external aids. Indeed, Intons-Peterson and Fournier (1986) make a similar point and suggest that the use of external aids must be incorporated into theoretical models of memory. Perhaps the increased emphasis on understanding the relationship between environmental context and memory in recent empirical work (Davies \& Thomson, 1988; S. Smith, 1979) might be viewed as a step in this direction.

The fourth finding, that memory researchers are more likely to cite their expertise as the basis for recommendations, is closely linked to the fifth finding that when differences emerged, they did tend to be theoretically based. For example, the one area in which memory researchers were consistently different from the other groups was their personal usage and recommended usage of rhymes. Memory researchers were significantly less likely to rely on rhymes to remember and were also the only group to rank rhymes as one of their five least recommended strategies. The levels of processing literature (Craik \& Lockhart, 1972; Craik \& Tulving, 1975) have clearly demonstrated that attention to phonemic characteristics through orienting tasks that involve rhymes are ineffective mnemonic strategies. This well-known finding among memory researchers might have affected their responses. Similarly, memory researchers reported greater reliance on organization and less reliance on rehearsal than did nonmemory participants. Sixty-three percent of the memory psychologists included organization in their top five recommended techniques, as compared with only $37 \%$ and $31 \%$ for other psychologists and non- psychologists. Only half as many of the memory psychologists, on the other hand, recommended rehearsal (25\%), as compared with the other psychologists (49\%). Again, the enormous research literature demonstrating the benefits of organization over rehearsal for long-term memory (Mandler, 1979) may have affected the responses of the memory psychologists.

In closing, these data suggest that memory researchers, when queried, would suggest to others that a paper and pencil may be the most effective mnemonic device available. If pushed to recommend a technique to use when such external devices are not available, it appears that they would recommend general strategies such as rehearsal and organization, rather than the more exotic formal mnemonic systems. The emphasis of contemporary memory research on general strategies rather than formal mnemonic systems seems well placed and consonant with the present findings, but attempts to incorporate the use of external aids into theoretical models are needed. Hermann and Chaffin (1988) quote Francis Bacon, who several hundred years ago summarized the position of contemporary memory psychologists with respect to the fruitfulness of formal mnemonic devices for everyday memory function, when he stated that "feats can be performed with it [mnemonic techniques] that are marvelous and prodigious, but nevertheless it is a barren thing for human uses. It is not well contrived for providing assistance to the memory in serious business and affairs" (p. 167).

\section{REFERENCES}

BARTLETT, F. C. (1932). Remembering: A study in experimental and social psychology. Cambridge, England: Cambridge University Press.

Cavanaugh, J. C., Grady, J. G., \& Perlmutter, M. (1983). Forgetting and use of memory ajds in 20 to 70 year olds' everyday life. Intemational Journal of Aging \& Human Development, 17, 113-122.

Craik, F. I. M., \& LockharT, R. S. (1972). Levels of processing: A framework for memory research. Journal of Verbal Learning \& Verbal Behavior, 11, 671-684.

Craik, F. I. M., \& Tulving, E. (1975). Depth of processing and the retention of words in episodic memory. Joumal of Experimental Psychology: General, 104, 268-294.

Davies, G. M., \& Thomson, D. M. (Eds.). (1988). Memory in context: Context in memory. New York: Wiley.

Dixon, R. A., \& Hulrsch, D. F. (1983). Structure and development of metamemory in adulthood. Journal of Gerontology, 38, 682-688.

HarRIS, J. E. (1980). Memory aids people use: Two interview studies. Memory \& Cognition, 8, 31-38.

HerrmanN, D. J. (1982). Know thy memory: The use of questionnaires to assess and study memory. Psychological Bulletin, 92, 434-452.

Herrmann, D. J. (1983). Questionnaires about memory. In J. Harris \& P. Morris (Eds.), Everyday memory, actions and absent-mindedness (pp. 133-152). London: Academic Press.

HerrmanN, D. J., \& Chaffin, R. (1988). Memory in historical perspective: The literature before Ebbinghaus. New York: SpringerVerlag.

Intons-Peterson, M. J., \& Fournier, J. (1986). External and internal memory aids: When and how often do we use them? Journal of Experimental Psychology: General, 115, 267-280.

Mandler, G. (1979). Organization, memory, and mental structures. In C. R. Puff (Ed.), Memory, organization and structure (pp. 303320). New York: Academic Press. 
Morris, P. E. (1983). The validity of subjective reports on memory. In J. Harris \& P. Morris (Eds.), Everyday memory, actions and absentmindedness (pp. 153-172). London: Academic Press.

Perlmutrer, M. (1978). What is memory aging the aging of? Developmental Psychology, 14, 330-345.

Poon, L. W., Rubin, D., Wilson, B. (Eds.). (1989). Everyday cognition in adulthood and late life. Cambridge, England: Cambridge University Press.

Sмiтh, A. D. (1980). Age differences in encoding, storage, and retrieval. In L. W. Poon, J. L. Fozard, L. S. Cermak, D. Arenberg, \& L. W.
Thompson (Eds.), New directions in memory and aging (pp. 23-45). Hillsdale, NJ: Erlbaum.

SMITH, S. (1979). Remembering in and out of context. Joumal of Experimental Psychology: Human Learning \& Memory, 5, 460-471. WEST, R. (1985). Memory fitness over 40. Gainesville, FL: Triad Publishing.

(Manuscript received August 29, 1988; revision accepted for publication September 12, 1989.) 